\title{
O perfil das Crianças e Adolescentes atendidas no Programa Sentinela: Compreendendo o Fenômeno da Violência
}

\author{
The profile of Children and Adolescents in the Sentinel Program: Understanding the \\ Phenomenon of Violence
}

\author{
Karin Cristiane Freitag ${ }^{1}$
}

\begin{abstract}
Resumo:
Este trabalho surgiu do interesse em conhecer as complexidades das demandas do Programa Sentinela da cidade de Blumenau, para fazer um comparativo com o fenômeno da violência e suas diversas especificidades apresentadas na literatura. A partir deste interesse, foi realizada a intervenção e posteriormente um tracejo, que objetivou contribuir na confecção de um documento que apresentasse um perfil das crianças e adolescentes atendidas no Programa Sentinela de Blumenau, vítimas das diversas violências. Esse documento tem o intuito de colaborar com dados municipais, estaduais e nacionais. Tal intervenção teve como metodologia a pesquisa documental de cunho quantiqualitativo e levantamentos bibliográficos que contribuíram para analisar os dados levantados. O universo da pesquisa documental foram todas as crianças e adolescentes do referido programa, através dos prontuários de atendimentos. Os resultados deste trabalho apresentam o perfil das vítimas na perspectiva de gênero, idade, escolaridade, tipo de violência, raça/etnia, renda familiar, o vinculo com o agressor e, ainda, o órgão encaminhador da Medida de Proteção.
\end{abstract}

Palavras-Chave: Crianças. Adolescentes. Fenômeno. Violência. Programa Sentinela.

\begin{abstract}
:
This work appeared of the interest in there knew the complexities of the demands of the Program Sentry of the city of Blumenau, to do a comparative one with the phenomenon of the violence and you sweat several presented especificidades nacionalmente. From this interest, the intervention was carried out and subsequently one plans, at what it aims then, to contribute in the production of a document that presents a profile of the children and adolescents when Sentry was attended in the Program, victims of several violence. This document has the intention of collaborating with city, state and national data. Such an intervention
\end{abstract}

\footnotetext{
${ }^{1}$ Karin Cristiane Freitag é Assistente Social, formada pela FURB - Universidade Regional de Blumenau, com especialização em Enfrentamento da Violência contra Crianças e Adolescentes pela PUC - Pontífícia Universidade Católica do Paraná. Atuou no atendimento de crianças e adolescentes no setor privado em serviço de contra turno escolar e educacional; e, no setor público em programas de medidas de proteção de acolhimento institucional e no Serviço de Enfrentamento à Violência, Abuso e Exploração Sexual de Crianças, Adolescentes (Programa Sentinela). Atualmente, atua no Serviço Social empresarial. Email: karin_freitag@yahoo.com.br
} 
took the documentary inquiry of hallmark as a methodology quantiqualitativo and bibliographical liftings that contributed to analyse the lifted data. The universe of the documentary inquiry they were all the children and adolescents through the service handbooks. The results of this work present the profile of the victims in the perspective of type, age, schooling, type of violence, raça/etnia, familiar income, the bond with the aggressor and still, the guiding organ of the Measure of Protection.

Keywords: Children. Adolescents. Phenomenon. Violence. It plans Sentry.

\section{Introdução}

No presente artigo científico, o fenômeno da violência será nosso principal foco de estudo, buscando refletir, sobretudo, quais tipos de violências são praticadas contra crianças e adolescentes, tomando como objeto de estudo, os atendimentos do Programa Sentinela da cidade de Blumenau (2006).

O objetivo geral desse estudo é traçar o perfil das crianças e adolescentes atendidos no Programa Sentinela de Blumenau, sob a ótica da problemática da violência. A partir disso, os objetivos específicos são: Refletir sobre o fenômeno da violência contra crianças e adolescentes; Correlacionar as diversas ramificações da violência contra crianças e adolescentes; Identificar o Serviço de Enfrentamento à Violência, Abuso e Exploração Sexual de Crianças, Adolescentes e suas famílias e especialmente, com a discussão do presente artigo; apresentar dados sobre a violência e traçar um perfil das famílias atendidas no Programa Sentinela.

A violência praticada contra crianças e adolescentes é um fato cada vez mais evidente no Brasil e no mundo e precisa ser desmistificado na sua complexidade para, juntamente com ações eficazes, ser combatida.

O tema partiu da necessidade pessoal de compreender esse fenômeno (da violência) sob um olhar profissional, diante da vivência no campo de trabalho, mas principalmente, com o intuito de desenvolver uma prática profissional ligada aos interesses do Programa Sentinela.

Portanto, pensou-se em estruturar o estudo em dois capítulos, mais as considerações finais:

Primeiramente, procurou-se apresentar sucintamente sobre o fenômeno da violência praticado contra crianças e adolescentes, conceituando "a violência" no âmbito 
geral. A partir disso, o intuito é discorrer sobre as diversas formas de violência a que as crianças e adolescentes são submetidos, com ênfase especial para a violência sexual, ou abuso sexual, por se tratar de um tema abstruso.

A seguir, discorre-se também sobre o Serviço de Enfrentamento à Violência, Abuso e Exploração Sexual de Crianças e Adolescentes - Programa Sentinela de Blumenau. Neste capítulo, é apresentado o Programa Sentinela como a Política Pública do município de Blumenau que emerge para lidar com a demanda da violência infanto juvenil. Deste modo, destaca-se o público alvo do referido Programa, com os objetivos e metodologias de trabalho no enfrentamento e superação à violência. Neste mesmo capítulo aponta-se o perfil das crianças e adolescentes atendidas no Programa Sentinela, apresentando as principais características observadas.

Concluindo, as considerações finais abalizam um apanhado geral sobre o fenômeno da violência, com base no que foi traçado das famílias atendidas no Programa Sentinela de Blumenau, correlacionando também com dados apresentados durante o referencial do artigo.

\section{O Fenômeno da Violência contra Crianças e Adolescentes}

São muitas as discussões que se presencia acerca da violência contra o ser humano, principalmente por ser um tema causador de polêmica, às vezes de origem cultural e que por isso, tratado ainda pelo senso comum. Esse fenômeno vem sendo discutido pela sociedade e tratado de forma prioritária pelas Políticas Públicas, as quais tentam romper com os ciclos de violência que acompanham as pessoas desde seu primórdio e que estão cada vez mais evidentes nos dias atuais.

Para falar sobre a violência, suas formas e consequências, é importante que haja uma definição desse fenômeno. A Organização Mundial de Saúde define a violência como sendo,

[...] o uso da força física ou do poder real ou em ameaça, contra si próprio, contra outra pessoa, ou contra um grupo ou uma comunidade, que resulte ou tenha qualquer possibilidade de resultar em lesão, morte, dano psicológico, deficiência de desenvolvimento ou privação (WORLD HEALTH ORGANIZATION, 2002). 
Segundo a definição, a violência é um fato humano, que geralmente é social, pois acontece em todas as sociedades, não isentando a possibilidade de ser praticada de uma pessoa contra si própria. Consiste no uso da força física ou do poder, para dominar, causando danos muitas vezes irreversíveis, que podem variar desde danos psicológicos até à morte.

A definição da Organização Mundial da Saúde apresenta ainda, que a violência pode ser praticada contra um grupo, podendo este ser caracterizado por idades, gêneros, etnias, classes sociais, dentre outros. Aqui, o intuito é discorrer sobre a violência praticada contra um segmento da sociedade, o qual é alvo de atenção especial por se tratar de seres em desenvolvimento: crianças e adolescentes.

Segundo o Estatuto da Criança e do Adolescente (Lei no 8.069, 1990), em seu artigo 20: "Considera-se criança, para os efeitos desta Lei, a pessoa até doze anos de idade incompletos, e adolescentes aquela entre doze e dezoitos anos de idade." (BRASIL, 1990).

A questão da violência, mesmo sendo sempre ruim, fica ainda pior quando se pratica contra crianças e adolescentes, que por sua peculiaridade estão em fase de desenvolvimento, são incapazes de decidir por si só, pois ainda não possuem estrutura física e emocional suficientes para se defender, por isso merecem total atenção da sociedade para protegê-las (CUNHA, 2008).

Geralmente, crianças e adolescentes acabam sendo vítimas, por serem vistas como objetos de propriedade dos seus responsáveis e não como sujeitos de direitos. Trata-se de um fato que sempre permeou nossa sociedade e assim como outros grupos, sempre foram vítimas dos diversos tipos de violência, despertando-nos apenas recentemente a necessidade de romper com esse ciclo (CUNHA, 2008).

\section{Os Tipos de Violência}

No cenário do que se conceitua como violência contra crianças e adolescentes, pode-se caracterizá-la como tendo várias formas. Por essa caracterização, a violência é um tema muito polêmico e complexo, pois há diferentes modalidades que são específicas, mas que se complementam. Dentre suas diversidades tem-se o trabalho infantil, a exploração sexual comercial e a violência doméstica. Sobre os diferentes aspectos será discorrido a seguir. 
Na questão do trabalho infantil, entende-se que seja a exploração de crianças e adolescentes pelos donos dos meios de produção, sujeitando-as às desvantagens da situação de pessoas em desenvolvimento.

Segundo Hilbig (2006),

\begin{abstract}
Existem diversos motivos para as crianças e adolescentes se incorporarem ao mercado de trabalho. A pobreza é o principal. Outra causa importante é a demanda do mercado de trabalho por mão-deobra barata. Além do fato das crianças trabalharem por menos dinheiro, elas são mais facilmente disciplinadas e não estão organizadas em sindicatos.
\end{abstract}

Isso ocorre principalmente devido ao baixo nível de renda auferido pelos pais e responsáveis das crianças. Muitas vezes crianças e adolescentes acabam ingressando precocemente no mercado de trabalho para complementar a renda da família ou até assegurar esse sustento familiar. Sobretudo são empregos informais, com baixa qualificação e sem perspectiva de futuro.

Assim como o trabalho infantil, outra forma de violência contra crianças e adolescentes é a exploração sexual comercial. O Centro de Referência, Estudos e Ações sobre Crianças e Adolescentes define a exploração sexual como sendo, "[...] tipo de atividade em que as redes, usuários e pessoas usam o corpo de um menino, menina ou de adolescente para tirar vantagem ou proveito de caráter sexual com base numa relação de exploração comercial e poder." (LEAL, 1999, p. 10).

Desta forma, por se tratar de ato realizado com base numa relação de poder sobre crianças e adolescentes, a exploração sexual comercial é uma violência considerada crime. Assim como os demais tipos de violência, a exploração sexual comercial também tem várias configurações, podendo ser nas formas de prostituição infanto juvenil, pornografia, turismo sexual e tráfico.

A exploração sexual comercial e suas diversas formas é uma prática em que um adulto manipula crianças ou adolescentes oferecendo muitas vezes dinheiro em troca de favores de cunho sexual.

A violência doméstica, assim como a exploração sexual comercial, também é subdividida em várias formas, mas está diretamente ligada à família e ao meio em que a 
criança/adolescente vive. Nesta divisão de violência doméstica, as principais são: o abandono, a negligência, violência psicológica, violência física e a violência sexual.

Para discorrer sobre as formas da violência doméstica, o conceito de Azevedo e Guerra (2000 apud CUNHA, 2008, p. 4) traz a fundamentação principal de como a violência se configura. Segundo os autores, violência doméstica é "todo ato ou omissão praticado por pais, parentes ou responsáveis capazes de causar dano físico, psicológico e sexual, implicando numa transgressão de poder, dever de proteção do adulto e numa coisificação da infância".

Geralmente, os responsáveis pela prática da violência doméstica contra crianças e adolescentes, são seus responsáveis, os quais deveriam garantir a proteção e segurança, mas ao contrário, tratam crianças/adolescentes como objetos que não têm vontade própria.

Como violência física, entende-se que é quando alguém causa dano por meio da força física. Dano que pode ser percebido como: lesões internas, externas ou ambas. Nos casos de violência física, os pais ou responsáveis algumas vezes quando estão agredindo os filhos, acreditam que estão educando. Isso ocorre porque a agressão física seria "um castigo" para "punir" o que se fez de errado, como se o erro fosse algo isolado da criança e do adolescente. Pelo contrário, errar é uma prática normal do ser humano e deve ser compreendido como ato importante para o desenvolvimento de todos, que deveria ser usado pelos responsáveis como pretexto de diálogo, aproximação, afeto e limite.

O abandono e a negligência também são formas de violência, nas quais o adulto responsável pela criança/adolescente a rejeita ou é omissa, sem assumir uma responsabilidade por sua criação e seus cuidados como a saúde, a vida, alimentação, educação, dignidade, etc, conforme previstos no art. 4을 do Estatuto da Criança e do Adolescente (BRASIL, 1990).

Não menos séria do que as outras formas de violência, a violência psicológica consiste na ação que prejudica a identidade ou desenvolvimento da criança e do adolescente, como ameaças, humilhações, chantagem, cobranças de comportamentos, dentre outros. Ao contrário do que se imagina, a violência psicológica é muito séria, causa um dano à auto-estima que às vezes pode ser irreparável. A diferença das outras violências à violência psicológica é que essa última é subjetiva e por isso mais difícil de ser 
diagnosticada.

\section{A Violência Sexual contra Crianças e Adolescentes}

A violência sexual contra crianças e adolescentes é uma das mais sérias que acontecem, pois muitas vezes pode causar danos físicos, psicológicos e comportamentais que, se não tratados de forma especializada podem causar danos irreversíveis.

Considerada um ramo da violência doméstica, a violência sexual pode também acontecer no âmbito da família e é popularizada por muitos nomes, sendo um dos principais: abuso sexual. Aqui será denominado o vocábulo abuso sexual extrafamiliar e intrafamiliar.

Existem várias considerações para elucidar o que é abuso sexual, sendo o conceito a seguir bastante significativo. Para Vaz (1997, p. 17), abuso sexual é,

[...] todo ato ou jogo sexual em que um adulto submete uma criança e/ou um adolescente com intenção de estimular-se ou satisfazer-se sexualmente, com ou sem o consentimento da vítima, impondo-se pela força física ou ameaças nas classes de baixa renda e pela sedução nas demais classes, podendo variar desde a ausência de contato sexual até os atos sexuais com ou sem penetração.

Segundo o autor, o abuso sexual é toda ação na qual uma pessoa através do poder que lhe concerne como adulto, submete uma criança e/ou adolescente à realização de práticas sexuais, que variam desde a sedução até o ato consumado.

Portanto, o abuso sexual não consiste apenas na relação em que há um contato físico ou penetração, mas incide ainda, outras formas que culminam em abuso sexual, podendo ser através do exibicionismo ${ }^{2}$, do voyerismo ${ }^{3}$, ou da verbalização de atividades sexuais, todas para despertar o interesse sexual da criança e/ou adolescente ou chocá-las.

O abuso sexual é uma violência que configura uma situação de ultrapassagem de limites, de violação de direitos humanos, de poder e de papéis, mas ainda, do nível de desenvolvimento da criança/adolescente, além do que ela consegue consentir (LEAL;

\footnotetext{
${ }^{2}$ Exibicionismo - Consiste no impulso para se despir ou exibir os órgãos genitais. A intenção é chocar a vítima. O exibicionista é motivado por esta reação.

${ }^{3}$ Voyerismo - Consiste na obtenção de prazer sexual pela observação dissimulada de cenas de caráter íntimo ou erótico. Curiosidade por tudo o que é privado ou íntimo.
} 
LEAL, 2000), podendo ser caracterizada em sua autoria como abuso sexual intrafamiliar (doméstico) e extrafamiliar, que por sua vez, é cometido por adultos conhecidos sem laços consangüíneos e/ou desconhecidos.

Por abuso sexual intrafamiliar entende-se que é todo ato de cunho sexual, com ou sem contato físico ou uso de força, praticado contra uma criança e/ou adolescente, por um adulto que tenha qualquer afinidade de responsabilidade com a mesma (CUNHA, 2008).

Portanto, o abuso sexual quando cometido no âmbito familiar, geralmente é praticado por alguém que tem uma ligação de confiança com a criança ou adolescente, ou seja, algum adulto em que a criança confia; pai, mãe, tios (as), primos (as), padrasto, avós e outros.

Exatamente pelo abuso sexual ser praticado por pessoas de relação da criança e do adolescente, fica ainda mais difícil de comprovar a violência, pois muitas vezes o abuso não é praticado através de força física e sim pela sedução e relação de poder, não deixando marcas visíveis.

\section{O Serviço de Enfrentamento à Violência, Abuso e Exploração Sexual de Crianças e Adolescentes (Programa Sentinela) de Blumenau/SC}

A Lei 8.090 de 1990 (o ECA) surge para contribuir com o público infanto-juvenil, que, até então, não era visto como pessoas portadoras de direitos e somente a partir da vigoração da citada Lei, tem recebido um novo olhar. $\mathrm{O}$ art. 86 prevê que "A política de atendimento dos direitos da criança e do adolescente far-se-á através de um conjunto articulado de ações governamentais e não-governamentais, da União, dos estados, do Distrito Federal e dos municípios." (BRASIL, 1990).

Com isso, as Políticas de atendimentos às crianças e adolescentes surgiram para preconizar esses direitos, assegurados em Lei, através de um conjunto de ações que vem ao encontro destas necessidades.

Segundo o art. 98 ainda, 
As medidas de proteção à criança e ao adolescente são aplicáveis sempre que os direitos reconhecidos nesta Lei forem ameaçados ou violados:

I - por ação ou omissão da sociedade ou do Estado;

II - por falta, omissão ou abuso dos pais ou responsáveis;

III - em razão da sua conduta (BRASIL, 1990).

Em virtude da imprescindível necessidade de intervenção profissional para o cumprimento de medidas de proteção, em 1998 a cidade de Blumenau, implantou o PROPRIÁ - Programa de Proteção à Infância e à Adolescência com o intuito de atender esta demanda.

Com o aumento desta demanda, houve discussões sobre a necessidade de realizar um trabalho, que incluía além de atendimentos especializados, medidas de prevenção e instrumentalização da comunidade sobre a violência sexual, física e exploração sexual. Surge em setembro de 2005 o Serviço de Enfrentamento à Violência, Abuso e Exploração Sexual de Crianças e Adolescentes (BLUMENAU, 2006).

Portanto, o Programa Sentinela veio ao encontro da necessidade em realizar um trabalho no enfrentamento da violência sexual e física, ampliando suas ações para além do atendimento terapêutico, social e especializado, articulando-as com a rede de serviços sócioassistenciais com a finalidade de prevenir a violência contra crianças e adolescentes.

Em concordância com o Plano Nacional de Enfrentamento à Violência Sexual contra Crianças e Adolescentes; a LOAS - Lei Orgânica de Assistência Social e a PNAS - Política Nacional de Assistência Social, o Programa Sentinela é um serviço que oferece acolhimento especializado às crianças e adolescentes vítimas de abuso ou exploração sexual e violência física, bem como à sua família, tendo o intuito de oferecer fortalecimento e superação da violação dos direitos e da violência vivenciada (BRASIL, 1993).

O Programa Sentinela de Blumenau está situado no âmbito de proteção social especial de média complexidade o qual procura, através de uma equipe interdisciplinar formada por psicólogos, assistentes sociais, pedagoga e educadores, preservar os vínculos familiares e comunitários de crianças e adolescentes que tiveram os seus direitos violados, rompendo o ciclo de violência vivenciado.

Os encaminhamentos das Medidas de Proteção às famílias em situação de risco são 
realizados pelos órgãos competentes oficiais como o Conselho Tutelar, Poder Judiciário, Ministério Público, Delegacias de Polícia e demais redes de serviços do município. A partir dos encaminhamentos, as famílias passam por procedimentos técnicos que vão desde o acolhimento (da família), perpassando pelos atendimentos individuais (psicológicos e/ou sociais) e em grupos, encaminhamentos para oficinas e demais serviços da rede pública, até o desligamento da família, após avaliações técnicas das equipes. Ressalta-se que todos os procedimentos realizados são avaliados individualmente pelas equipes interdisciplinares e a partir disso, traçado um plano de atendimento junto com a família, dependendo da disponibilidade da mesma e da gravidade da violência.

Em relação à prevenção, o Programa busca apresentar-se na cidade em unidades escolares, ambulatórios, empresas ou conforme solicitado, no intuito de divulgar os serviços de atendimento e esclarecer sobre o fenômeno da violência, mas principalmente, para incentivar a sociedade a denunciar os maus tratos contra crianças e adolescentes.

\section{O Perfil das Famílias Atendidas no Programa Sentinela de Blumenau/SC}

O público alvo do Programa Sentinela são crianças e adolescentes, bem como suas respectivas famílias e/ou responsáveis, vítimas de violência física, sexual ou exploração sexual. Para apresentar os dados desse artigo, foi realizada pesquisa documental no Programa Sentinela, com prévia autorização, juntamente com a coordenadora da referida instituição.

As informações utilizadas nesta pesquisa foram coletadas e analisadas a partir da última atualização de dados, realizada em 23 de outubro de 2009. Observou-se o universo de 406 crianças e adolescentes atendidos no Programa Sentinela vítimas de violência física, sexual e exploração sexual.

As tabelas números 1 e 2 são referente ao gênero, idade das crianças e adolescentes e os tipos de violências sofridas. 
Tabela 1 - referente gênero, idade e tipo de violência (Feminino)

\begin{tabular}{c|c|c|c|c|c|c}
\hline & \multicolumn{7}{c}{ Feminino } \\
\hline & 0 a 3 anos & 4 a 6 anos & 7 a 9 anos & 10 a 12 anos & 13 a 15 anos & 16 a 18 anos \\
\hline Viol. Sexual & 17 & 20 & 25 & 47 & 41 & 16 \\
\hline Viol. Física & 2 & 7 & 9 & 19 & 11 & 13 \\
\hline Exploração & 0 & 0 & 0 & 1 & 6 & 2 \\
\hline Total & $\mathbf{1 9}$ & $\mathbf{2 7}$ & $\mathbf{3 4}$ & $\mathbf{6 7}$ & $\mathbf{5 8}$ & $\mathbf{3 1}$ \\
\hline
\end{tabular}

Fonte: Programa Sentinela - Blumenau

Tabela 2 - referente gênero, idade e tipo de violência (Masculino)

\begin{tabular}{c|c|c|c|c|c|c}
\hline & \multicolumn{7}{c}{ Masculino } \\
\hline & 0 a 3 anos & 4 a 6 anos & 7 a 9 anos & 10 a 12 anos & 13 a 15 anos & 16 a 18 anos \\
\hline Viol. Sexual & 2 & 17 & 23 & 20 & 29 & 6 \\
\hline Viol. Física & 4 & 11 & 19 & 12 & 18 & 6 \\
\hline Exploração & 0 & 0 & 0 & 0 & 2 & 1 \\
\hline Total & $\mathbf{6}$ & $\mathbf{2 8}$ & $\mathbf{4 2}$ & $\mathbf{3 2}$ & $\mathbf{4 9}$ & $\mathbf{1 3}$ \\
\hline
\end{tabular}

Fonte: Programa Sentinela - Blumenau

Percebe-se que em relação ao gênero (tabela 1 e 2 acima) enquanto crianças e adolescentes do sexo feminino totalizam 236 vítimas dos diversos tipos de violência, o sexo masculino totaliza 170 vítimas. No quesito violência sexual, 166 meninas foram vítimas, contra 97 meninos vítimas da mesma violência. Isso reflete um fator marcante, levando em consideração que no quesito violência física não há grande diferença de números de vitimas na questão de gênero. Já na exploração sexual, três vezes mais meninas do que meninos foram vítimas de exploração sexual, novamente apontando para a questão de gênero.

Há autores que correlacionam, principalmente a violência sexual, com a questão de gênero. Para Schreiner (2008, p. 1):

A violência de gênero traduz representações sociais historicamente construídas, determinando a homens e mulheres lugares diferenciados na sociedade, diferença atravessada por relações de poder notadamente assimétricas. Esta assimetria é mantida, muitas vezes, tendo a violência como instrumento e, mais especificamente a violência sexual nas suas mais variadas manifestações.

Segundo a autora, a violência de gênero, aqui caracterizada como a violência sexual 
e a exploração, é explicada pela construção das relações de poder construídas historicamente na sociedade. Acredita-se que por essa construção, mulheres são vistas como pessoas que devem ser subordinadas aos homens, explicando o porquê da violência sexual ser tão expressiva em relação ao sexo masculino.

Observa-se que tanto gênero, acima mencionado, como também a baixa escolaridade, servem de influência para a violência, conforme a tabela número 3 :

Tabela 3 - referente gênero, escolaridade e tipo de violência

\begin{tabular}{c|c|c|c|c|c|c|c}
\hline & \multicolumn{3}{|c|}{ Feminino } & \multicolumn{3}{c|}{ Masculino } & Total \\
\hline & Ed.Infantil & Ens.Fund & Ens.Med & Ed.Infantil & Ens.Fund & Ens.Med & \\
\hline Vio. Sexual & 35 & 125 & 15 & 9 & 75 & 4 & $\mathbf{2 6 3}$ \\
\hline Viol. Física & 8 & 50 & 7 & 9 & 56 & 1 & $\mathbf{1 3 1}$ \\
\hline Exploração & 0 & 10 & 0 & 0 & 1 & 1 & $\mathbf{1 2}$ \\
\hline Total & $\mathbf{4 3}$ & $\mathbf{1 8 5}$ & $\mathbf{2 2}$ & $\mathbf{1 8}$ & $\mathbf{1 3 2}$ & $\mathbf{6}$ & $\mathbf{4 0 6}$ \\
\hline
\end{tabular}

Fonte: Programa Sentinela - Blumenau

Em relação ao grau de escolaridade, percebe-se que quase $70 \%$ das crianças e adolescentes vítimas de algum tipo das violências em questão, são estudantes do ensino fundamental, compreendido do período entre 5a a $8^{a}$ série. Com isso, compreende-se também que a faixa etária que mais fica evidente às situações de violência são crianças e adolescentes entre 9 e 15 anos.

Já no que refere à etnia das crianças/adolescentes, percebe-se que a branca aponta a maior incidência das violências, seguida da parda e depois da negra. Essa incidência explica-se, talvez, pela cidade de Blumenau ter uma colonização européia e com isso, maior etnia branca. Outra ponderação significativa é a violência sexual ser expressivamente predominante referente a outras violências, em todas as etnias, como expõe a tabela número 4.

Tabela 4 - referente raça/etnia e tipo de violência.

\begin{tabular}{c|c|c|c|c}
\hline & Branca & Parda & Negra & Total \\
\hline Viol. Sexual & 220 & 38 & 5 & $\mathbf{2 6 3}$ \\
\hline Viol. Física & 115 & 15 & 1 & 131 \\
\hline Exploração & 5 & 5 & 2 & 12 \\
\hline Total & $\mathbf{3 4 0}$ & $\mathbf{5 8}$ & $\mathbf{8}$ & $\mathbf{4 0 6}$ \\
\hline
\end{tabular}

Fonte: Programa Sentinela - Blumenau 
Em comparação com os dados apresentados nacionalmente no Plano Nacional de Promoção, Proteção e Defesa do Direito de Crianças e Adolescentes à Convivência Familiar e Comunitária, a etnia negra e/ou parda, trata-se de mais que o dobro de vítimas de etnia branca. Segundo os dados do referido Plano ${ }^{4}, 1.904$ crianças e adolescentes de etnia parda ou negra foram vítimas de violência sexual, contra 983 crianças e adolescentes de etnia branca.

Em seguida observa-se a renda familiar e sua influência nos diversos tipos de violência.

Tabela 5 - referente à renda familiar e tipo de violência:

\begin{tabular}{c|c|c|c|c|c|c}
\hline & Até 1SM & 1SM até 2SM & 2SM até 3SM & Acima de 3SM & Não especif & Total \\
\hline Viol. Sexual & 42 & 103 & 77 & 34 & 2 & $\mathbf{2 5 8}$ \\
\hline Viol. Física & 11 & 50 & 47 & 22 & 0 & $\mathbf{1 3 0}$ \\
\hline Exploração & 1 & 6 & 3 & 1 & 1 & $\mathbf{1 2}$ \\
\hline Total & $\mathbf{5 4}$ & $\mathbf{1 5 9}$ & $\mathbf{1 2 7}$ & $\mathbf{5 7}$ & $\mathbf{3}$ & $\mathbf{4 0 0}$ \\
\hline
\end{tabular}

Fonte: Programa Sentinela - Blumenau

Discorre-se na tabela 5, a renda familiar, tendo expressividade na faixa salarial entre 1 a 3 salários mínimos. Entende-se que a situação de vulnerabilidade social da família pode ter relação com a prática das violências, principalmente com a violência sexual. Porém, acredita-se que com a necessidade dos pais e/ou responsáveis em ter uma longa jornada de trabalho, as crianças e adolescentes ficam mais expostas, sem a presença da figura de proteção na casa, tornando-os mais suscetíveis à violência.

Outro fator importante de exposição para crianças e adolescentes é o ambiente familiar ser marcado pelo uso de substâncias psicoativas, fazendo-os mais uma vez vítimas de mais uma incidência.

Entretanto, sabe-se que a violência praticada contra crianças e adolescentes em Blumenau, não acontece necessariamente nas classes menos favorecidas. Pelo contrário, a violência fica menos evidente nas classes bem sucedidas, devido às condições financeiras que permitem encobrir os fatos ocorridos.

Contudo, em todas as classes sociais, independente do tipo de violência, os

\footnotetext{
${ }^{4}$ Dados obtidos do Plano Nacional de Promoção, Proteção e Defesa do Direito de Crianças e Adolescentes à Convivência Familiar e Comunitária de 2005, extraídos do Ministério de Desenvolvimento Social e Combate à Fome em 10/12/2006.
} 
familiares aparecem como principais agressores, conforme a tabela a seguir:

Tabela 6 - referente à violência sexual, gênero e vínculo com o agressor

\begin{tabular}{l|c|c|c|c|c|c|c|c|c|c|c|c}
\hline \multicolumn{2}{l|}{ Violência Sexual } & & & & & & & & & & Total \\
\hline & Pai & Mãe & Pad & Mad & Avô & Avó & Irmão & Irmã & Outros & Outros & O \\
próprio & \\
\hline Fem & 37 & 0 & 34 & 0 & 9 & 1 & 3 & 1 & 27 & 58 & 2 & 172 \\
\hline Masc & 5 & 0 & 5 & 1 & 1 & 1 & 9 & 2 & 18 & 39 & 10 & 91 \\
\hline Total & $\mathbf{4 2}$ & $\mathbf{0}$ & $\mathbf{3 9}$ & $\mathbf{1}$ & $\mathbf{1 0}$ & $\mathbf{2}$ & $\mathbf{1 2}$ & $\mathbf{3}$ & $\mathbf{4 5}$ & $\mathbf{9 7}$ & $\mathbf{1 2}$ & $\mathbf{2 6 3}$ \\
\hline
\end{tabular}

Fonte: Programa Sentinela - Blumenau

Em relação à violência sexual praticada contra crianças e adolescentes tendo algum vínculo com o agressor, percebe-se que o pai, seguido do padrasto, são os agressores mais significativos, tendo em vista o grau de proteção que deveriam ter. Em relação aos outros familiares e, o denominado apenas como outros, também aparecem com um número expressivo, tratando-se de tios, primos, "vôdrasto" e conhecidos, como vizinhos, etc. Entretanto, da mesma forma, todos os envolvidos com a violência sexual acima representado, dispõe de um grau elevado de confiança em relação às vítimas.

Um fato importante de ser observado é que em relação à violência sexual, as mães não aparecem como violadoras, entretanto, na tabela 7, que refere a violência física, a mãe aparece expressivamente como agressora, confirmando que a agressão física ainda está muito ligada à questão de "punir" para "educar".

Tabela 7 - referente à violência física, gênero e vínculo com o agressor:

\begin{tabular}{c|c|c|c|c|c|c|c|c|c|c|c}
\hline \multicolumn{4}{c|}{ Violência Física } & & & & & & & & Total \\
\hline & Pai & Mãe & Pad & Mad & Avó & Avô & Irmão & Irmã & Fam & Outros & \\
\hline Fem & 11 & 29 & 5 & 5 & 1 & 0 & 3 & 0 & 0 & 5 & 59 \\
\hline Masc & 19 & 24 & 10 & 3 & 1 & 1 & 3 & 0 & 3 & 8 & 72 \\
\hline Total & $\mathbf{3 0}$ & $\mathbf{5 3}$ & $\mathbf{1 5}$ & $\mathbf{8}$ & $\mathbf{2}$ & $\mathbf{1}$ & $\mathbf{6}$ & $\mathbf{0}$ & $\mathbf{3}$ & $\mathbf{1 3}$ & $\mathbf{1 3 1}$ \\
\hline
\end{tabular}

Fonte: Programa Sentinela - Blumenau

Diante do quadro acima apresentado, o pai também aparece como figura significante quando se fala em agressão. Isso reflete que a violência física está intimamente originada nas relações familiares e, como já mencionado no presente trabalho, pode também ser considerada cultural. 
Já no que se refere à exploração sexual comercial, o agressor não está ligado diretamente à família, conforme tabela abaixo:

Tabela 8 - referente exploração sexual, gênero e vínculo com o agressor :

\begin{tabular}{c|c|c|c|c|c|c|c|c|c|c|c}
\hline \multicolumn{2}{c|}{ Exploração Sexual } & & & & & & & & & Total \\
\hline & Pai & Mãe & Pad & Mad & Avó & Avô & Irmão & Irmã & $\begin{array}{c}\text { Outros } \\
\text { Fam }\end{array}$ & Outros & \\
\hline Fem & 0 & 0 & 0 & 0 & 0 & 0 & 0 & 0 & 0 & 10 & 9 \\
\hline Masc & 0 & 0 & 0 & 0 & 0 & 0 & 0 & 0 & 0 & 2 & 2 \\
\hline Total & $\mathbf{0}$ & $\mathbf{0}$ & $\mathbf{0}$ & $\mathbf{0}$ & $\mathbf{0}$ & $\mathbf{0}$ & $\mathbf{0}$ & $\mathbf{0}$ & $\mathbf{0}$ & $\mathbf{1 2}$ & $\mathbf{1 2}$ \\
\hline
\end{tabular}

Fonte: Programa Sentinela - Blumenau

Confirma-se através da tabela acima que, em relação a exploração sexual, as vítimas não tem vínculos com o agressor, ou pelo menos não faz parte do círculo parental. Isso ocorre porque em geral a exploração sexual está ligada à prostituição, na qual as vítimas são "convencidas" de que o corpo pode ser usado como troca por dinheiro.

Diante dos tipos de violência apresentados, reflete-se sobre a responsabilidade dos órgãos de encaminhamento da medida de proteção.

Tabela 9 - referente órgão encaminhador, gênero e tipo de violência

\begin{tabular}{c|c|c|c|c|c|c|c}
\hline & \multicolumn{3}{|c|}{ Feminino } & \multicolumn{3}{c}{ Masculino } & Total \\
\hline & CT & Judiciário/MP & Outros & CT & Judiciário/MP & Outros & \\
\hline Viol. Sexual & 174 & 2 & 4 & 71 & 1 & 11 & $\mathbf{2 6 3}$ \\
\hline Viol. Física & 60 & 0 & 2 & 69 & 0 & 0 & 131 \\
\hline Exploração & 7 & 1 & 2 & 2 & 0 & 0 & 12 \\
\hline Total & $\mathbf{2 4 1}$ & $\mathbf{3}$ & $\mathbf{8}$ & $\mathbf{1 4 2}$ & $\mathbf{1}$ & $\mathbf{1 1}$ & $\mathbf{4 0 6}$ \\
\hline
\end{tabular}

Fonte: Programa Sentinela - Blumenau

Diante do exposto, observa-se que o Conselho Tutelar é o órgão que realizada o maior número de encaminhamentos para a Medida de Proteção ao Programa Sentinela, cumprindo assim com suas competências previstas no Estatuto da Criança e do Adolescente. Isso acontece porque o Conselho Tutelar é acessível à família e à sociedade que com freqüência informa as situações de risco contra crianças e adolescentes. Posteriormente, o Conselho Tutelar verifica as situações e encaminha para um dos programas municipais que atendam às necessidades da família. 


\section{Considerações Finais}

A questão da violência é um assunto extremamente complexo e precisa ser analisado sob o aspecto histórico e em diferentes contextos.

$\mathrm{Na}$ busca do que se compreende como violência, percebe-se que mesmo com suas diversas ramificações, a violência ainda se caracteriza como algo cultural, que sempre acompanhou o ser humano e por ser social, sempre fará parte da história das pessoas, necessitando assim de um conjunto de ações de prevenção social.

Percebe-se que ainda não está claro no contexto social, as crianças e adolescentes como pessoas portadoras de direitos e principalmente como seres em desenvolvimento. Observa-se que o ciclo de violência praticada contra crianças e adolescentes ainda é cultural, pois no caso da violência física intrafamiliar, as "surras" infelizmente fazem parte dos métodos mais utilizados para educar as crianças. No que diz respeito às outras violências, como a sexual, por exemplo, as crianças e os adolescentes não são poupados das mais perversas atrocidades, que às vezes causam danos irreparáveis, por não ter um cuidado protetivo de um adulto, que é quem deveria dispor toda a segurança e conforto aos pequenos.

Esse fato acontece pelo motivo da violência e suas diversas ramificações se encontrarem diretamente ligadas nas relações familiares, entre seus membros, junto às pessoas que deveriam garantir a proteção, os cuidados, afetividade, entretanto, são nos ambientes familiares que expressivamente são identificadas as mais diversas violências.

Em relação á violência sexual doméstica por exemplo, a maioria dos abusadores são pessoas dos vínculos familiares das crianças e ainda, são pessoas que sofreram algum tipo de violência quando criança e reproduzem uma violência agora, após a maioridade e formação da família.

Embora os resultados da pesquisa apontarem a violência como algo que acontece nos grupos sociais mais fragilizados, sabe-se que as classes sociais mais altas também sofrem com a violência, apenas as situações não aparecem escancaradamente.

Nosso papel como multiplicadores do Enfrentamento à Violência contra crianças e adolescentes é desmistificar essa problemática, refletindo sobre o seu enfrentamento social, desconstruindo o mito que a violência aparece apenas nas classes menos favorecidas. 
Acredita-se que, nesse contexto, deve-se interferir na formação da subjetividade das pessoas, e contribuir para romper com a cultura da violência, como sendo parte das vidas das pessoas que passa de geração em geração.

\section{Referências}

BLUMENAU. Prefeitura Municipal. Secretária da Saúde. Programa sentinela. Blumenau, 2006.

BRASIL. Estatuto da criança e do adolescente: Lei no 8.069 de 13 de julho de 1990. Brasília. Disponível em: <http://www.planalto.gov.br/ccivil_03/leis/L8069.htm.>. Acesso em: 2 set. 2006.

BRASIL. Ministério do Desenvolvimento Social e Combate à Fome. Lei $n 8.742$ de 7 de dezembro de 1993. Brasília. Disponível em:

<http://www.planalto.gov.br/ccivil_03/leis/L8742.htm.>. Acesso em: 2 set. 2006.

BRASIL. Secretaria Especial dos Direitos Humanos. Plano nacional de promoção, proteção e defesa do direito de crianças e adolescentes à convivência familiar e comunitária. Brasília: Conanda, 2006.

CUNHA, M. L. C. Curso de pós-graduação no enfrentamento da violência contra crianças e adolescentes: compreendendo o fenômeno. Curitiba: PUCPR, 2008. Módulo I.

HILBIG, S. Trabalho infantil no Brasil: dilemas e desafios. Disponível em: <http://www.dhnet.org.br/denunciar/brasil_2001/cap4_trabalho_infantil.htm>. Acesso em: 2 set. 2006.

LEAL, M. L. P. A exploração sexual comercial de meninos, meninas e adolescentes na América Latina e Caribe. Brasília: CECRIA, 1999. Relatório Final.

LEAL, M. L.; LEAL, M. F. (Org.). Tráfico de mulheres, crianças e adolescentes para fins de exploração sexual no Brasil. Brasília: CECRIA, 2000. Projeto de Pesquisa.

SCHREINER, M. T. O abuso sexual numa perspectiva de gênero: o processo de responsabilização da vítima. Florianópolis: EDUFSC, 2008.

VAZ, M. A situação do abuso sexual e da exploração sexual comercial contra crianças e adolescentes no Brasil. In: COSTA, J. J. (Coord.). Rompendo o silêncio: seminário multiprofissional de capacitação sobre abuso e exploração sexual de crianças e adolescentes. São Luis: CEDECA, 1997. p. 13-17.

WORLD HEALTH ORGANIZATION. Violence. 2002. Disponível em: <http://www.who.int/topics/violence/en/>. Acesso em: 2 set. 2006.

Recebido em: 22/10/2010

Aprovado em: 20/11/2010 